\title{
An Analysis on the Health Status of the Chinese Elderly
}

\author{
By Jianjun $\mathrm{Ji}^{*}$ \\ Lauren R. Bollaert ${ }^{\dagger}$
}

\begin{abstract}
This study examines the health status of the Chinese elderly by using the 2006 China National Rural and Urban Elderly Survey data. It presents the current top twenty-one diseases and their variations among the Chinese elderly. The study tests the hypothesis that health status is associated with socioeconomic characteristics, demographic characteristics, and the psychological wellbeing of the contemporary Chinese elderly. The study also examines the correlations between health status and variables of socioeconomic characteristics, demographic characteristics, and the psychological wellbeing. The study is conducted by utilizing statistical methods of Chi-Square significance test, measures of association such as Cramer's V, Tau-c, and Pearson's correlation coefficient. The findings disclose a comprehensive picture of the common diseases, variations, and the health status, as well as its links with the stated variables. The results uncover a unique feature of the health status of the Chinese elderly that is rarely documented in scholarly literature. Policy implications are also addressed. ${ }^{1}$
\end{abstract}

Keywords: Chinese elderly, Common diseases, Health status, Psychological wellbeing, Socioeconomic-demographic characteristics.

\section{Introduction}

China is in a fast population-aging process. The nation-wide application of medical technology in the country has lifted living standards and prolonged longevity. Consequently, this leads to a changing age structure and an increasing percentage of elderly people in the total population (Hu and Khan 1997). Additionally, the implementation of the One-Child Policy, which started in the early $1980 \mathrm{~s}$, brought about the decline of the country's total fertility rate from 6 children in the 1950 s to 1.8 children in the 2010s, and consequently accelerates the aging process of the elderly population in China (Hesketh et al. 2005). According to an estimate by the United Nations, Chinese society has already entered the phase of an older population (United Nations 2011-2012). The elderly, aged 60 years old and above, account for 168.5 million, or 12.5 percent of the total population. It is projected that by the year 2050, China's elderly population will reach about 300 million, which would equal about 20 percent of the total population (United Nations 2010). In light of this ongoing

\footnotetext{
* Professor of Sociology, University of Wisconsin-Eau Claire, USA.

${ }^{\dagger}$ Senior Research Apprentice, University of Wisconsin-Eau Claire, USA.

${ }^{1}$ Funds to support the project came from the University of Wisconsin-Eau Claire Summer Research Experiences for Undergraduates Program, 2015
} 
trend, China is becoming a fast greying-society and faces unprecedented challenges.

Aging Theory suggests that as a population ages, people's health status will undergo gradual and unfavorable changes in multiple aspects (Henslin 2008), such as genetic changes in DNA (deoxyribonucleic acid), biological changes in strength and vitality, psychological changes in memory and emotions, sociological changes in roles and status, political changes in power and conflict, and so on. Though these changes would occur and vary from person to person, one common trend of the aging population is that the overall health status of the elderly will inevitably deteriorate as an unfavorable outcome (Putman 2002). Foreseeing that China has such a large elderly population and is experiencing such a fast aging process (Chen and Liu 2009), scholars and researchers are becoming more interested in elderly-related issues in Chinese society. This study represents a continuous effort to focus on the issues of the Chinese elderly in terms of their health status. It attempts to examine the following areas: the health status of the Chinese elderly both in urban and rural areas; the common diseases prevailing among the Chinese elderly population; the variations of these diseases among the elderly; the correlations between health status and social and economic statuses, social resources, demographic characteristics, and psychological wellbeing of the Chinese elderly; and the associations between health status and social and economic statuses, demographic variables, and psychological wellbeing, as well as with their social resources.

Though research on the Chinese elderly has been conducted in multiple areas in recent years, the study of health status and common diseases is relatively rare in existing literature. Therefore, we expect to fill in the blanks of this literature by making use of the data from a nationwide survey collected by the China Research Center on Aging (CRCA) in December of 2006. Through the utilization of methods of statistical analysis such as percentage crosstabulation, Pearson's Correlation Coefficient (r), Chi-square significance test $\left(\chi^{2}\right)$, and the aptitude measures of Cramer's V and Tai-c (Fox 2002), this study will examine whether or not the top ten diseases (People's Daily 2014), are representative of the diseases among the Chinese elderly. Then the study will test the hypothesis that demographic characteristics, social, economic and social resource statuses, and psychological wellbeing of the Chinese elderly have correlations to their perceived health status.

In short, this study attempts to reach three objectives: to examine the common diseases and unfold an overall representation of the health status of the Chinese elderly aged 60 years and above; to analyze the correlations between health status and the variables of demographic, social, economic, social resources, as well as psychological wellbeing of the Chinese elderly; and to explore the associations made between health status and the indicators of demographic, social, economic characteristics, social resources, and psychological wellbeing of the Chinese elderly. 


\section{Theoretical Perspectives}

This study uses three theoretical frameworks that serve as the guidance and the theoretical ground for the predicted hypotheses: the Social Resource Theory; the Social Competence and Breakdown Theory; and the Political Economy Theory.

The Social Resource Theory separates resources into two different categories (Seibert et al. 2001). Personal resources, such as gender and age, belong to someone on an individual level, and are either ascribed or achieved. Social resources come from the connections and relationships with society and social groups. A large social network leads to greater exchanges of social resources and a better advantage concerning life quality. The theory implies that the elderly who show to have greater resources should show to have better health status.

Social Competence and Breakdown Theory suggests a process of negative consequences with multiple factors (Passuth and Bengston 1995). When an individual is mentally susceptible to their social environment, the negative messages that they receive are assimilated into their self-image, shaping other elements of overall life quality. Social competence is then related to individual breakdowns. As people age, the many new social roles and stereotypes come with poor connotations and help create a vulnerable mindset. Competence starts to diminish - leading to social breakdowns. This cycle noted in the Chinese elderly population would help to explain relationships between the studied life factors and health status.

The Political Economy of Age argues that the status of the elderly in a society can be attributed to the understanding of public policies, economic trends, and social structure of their specific culture (Bengston et al. 1999). Application of these factors helps to explain not only the social positions of the elderly, but also their quality of life. The changes of these variables are in a direct relationship with the variations of life satisfaction of the aging individuals. This theory will help to show correlations of the social and economic resources with health status of the Chinese elderly.

\section{Literature Review}

Research on the health status of the Chinese elderly is fast gaining popularity due to the increasing proportion of elderly people to younger people. However, this topic is still relatively new with a lot of missing information and there is a need for further exploration. This section examines the literature regarding the health status, common diseases, and their linkages with socioeconomic, demographic characteristics, and psychological in contemporary Chinese society.

In terms of chronic diseases afflicting the elderly people of China, a study of 70,000 households in the early 2000s found that the most prevalent issue was hypertension. It equaled 55.4 percent, with cardiac vascular disease and 
cerebrovascular disease as the next most common issues among the Chinese elderly (Zhang and Chen 2006). The results of this study were surprising to researchers at this time, because each of the diseases had jumped significant amounts of around 20 percent since the 1990s. Conclusions drawn from this study stated that this decline in the health of the Chinese elderly is due to their lack of provided health care support. The elderly reported less visits to health care facilities, showing a connection between medical insurance and health status of the Chinese elderly as well.

Demographic characteristics and social resources of the Chinese elderly were studied in comparison to health status by Liu and Zhang in 2004 (Liu and Zhang 2004). The data survey was conducted on Chinese citizens who were over the age of 80 in 1998 at the time of the survey. They found that age, sex, living arrangement, educational attainment, and occupational history were significantly associated with the self-reported health status rate among the oldest-old of the Chinese elderly. Also in their findings was the conclusion that low social status and negatively perceived health have a connection among this population. Males show to report much better health among the Chinese elderly than females, which shows a significant correlation between sex and health status. Those with a higher educational attainment level, and those not involved in agricultural occupations are associated with a significantly better selfreported health status. Living arrangement of the oldest Chinese elderly, however, is not associated with their health status, disconnecting a correlation between age and health.

Social resources and social characteristics have also shown correlations with the health status of the Chinese elderly. Resident location and support from children are two very important aspects in China, especially for the elderly population, in an ongoing shift from a very traditional society to a very modern one. One study done on the population of China in terms of residence, finds a great difference in health status among the variations of answers (Fang et al. 2009). Between those living in rural areas versus those living in urban areas, a large disparity in health status is shown. Individuals in rural areas show to experience a significant association in better reported health status than those individuals in urban areas. However, these differences also show to be decreasing as time progresses. Unfortunately the changes show that rather than urban health status improving, rural health status is declining - possibly due to air and water pollution from rapid industrialization, as stated in their conclusion and discussion. According to these findings, urban populations are less likely to visit health care providers and more likely to suffer from disabilities in life via illnesses.

When looking into support from children, Chinese elderly are significantly affected by it. Due to strong family-bonded traditions for care in later life, filial piety still holds much importance in the wellbeing of the elderly population of China (Cheng and Chan 2006). Children who do not show respect to their parents are chastised socially in China, harming both themselves and their elderly parents in the process. Filial piety and respect play a roll in health status, as much as it is a strong socially-moral factor. Elderly parents show to 
experience less stress as they age if they receive better care from their children. Family harmony also illustrates great importance in health status. Those who did not report filial piety in their family, but reported family harmony were also linked to experiencing better health statuses. Traditional society among the Chinese is very much noticed in this study.

In a study reported by the Institute of Southeast Asian Studies, economic characteristics also show to be significant in their relationship to health status (Chung 2006). Previous literature of a research study done in 2006 shows that economic advantage is directly related to individual health status. It found that economic resources, such as personal money saved, or at individual disposal, provide advantages to those respondents in both self and nurse reported health status. Those with more economic resources and personal savings show to be more likely to use professional medical care throughout their life, which is reflected in their health status. Medical insurance and state funding are also studied in the research and are consequently found to be related to health status. Those with private health insurance are more likely than those with state funded health insurance to seek medical help, which is also more than those individuals who reported to have neither insurance program - a direct connection to economic security and resources. Those who seek medical help show to have better reported health status.

A study done in focus groups on the Chinese elderly tested for quality of life based upon psychological health (Leung et al. 2004). It tested four different variables of psychological health in many different areas of 'mood states' of the elderly Chinese people. The results show the psychological health is statistically significant when compared to the life quality of the individual. The better the Chinese elderly respondents report to be in terms of psychological wellbeing indicators, the more likely they are to show an increased quality of life. This literature indicates that psychological wellbeing connects to the aspects of health status of the Chinese elderly.

The above literature shows linkages between health variables such as health status or diseases and socioeconomic, demographic, and psychological variables. This study will help fill in missing areas of information and give additional support to previous studies, because the data used in this study comes from a more recent survey and covers a greater number of Chinese elderly who account for a larger age range. It is expected that findings from this study will shed new light to a larger demographic sphere.

\section{Research Hypotheses}

In view of the above literature, we have developed the following hypotheses: Hypothesis 1: The perceived health status, in terms of the common diseases of the Chinese elderly, varies among the elderly population. Hypothesis 2: The perceived health status of the Chinese elderly is correlated with their social and economic characteristics, social resources, and demographic characteristics, and psychological wellbeing. Hypothesis 3: The 
perceived health status of the Chinese elderly is associated with their social and economic characteristics, social resources, and demographic characteristics, and psychological wellbeing. These hypotheses will be tested in this study.

\section{Methods}

\section{Data Source}

This research makes use of the data from a nationwide survey collected by the China Research Center on Aging (CRCA) in December of 2006. The survey was conducted among 20,083 elderly Chinese individuals, aged 60 and above, covering twelve provinces, two municipalities, and two autonomous regions throughout the country. This study however, will concentrate on 10 percent of the survey data, which comes to about 1,980 respondents. The sampled elderly were drawn through stratified and clustered methods. The data consists of information on psychological wellbeing of the Chinese elderly, as well as information on demographic characteristics, economic status, and social aspects.

\section{Measures}

All together there are eighteen variables that make up this study: one presumed dependent and seventeen presumed independent variables. The presumed dependent variable is the health status of the Chinese elderly, as reported by the individual respondents. Respondents were asked the question, "How do you view your health status?" It is re- coded and measured by a fivepoint-scale. (1) Very poor, (2) Poor, (3) So-so, (4) Good, and (5) Very good. This variable is ordinal. The seventeen presumed independent variables are divided into five categories: demographic characteristics such as gender, age, fertility, and marital status; social characteristics such as residence and education; economic characteristics such as economic security, economic perception, pension, and personal savings; social resources such as state stipend, support from children, and medical insurance; and finally, psychological wellbeing such as happiness, loneliness, family harmony, and memory loss.

Respondents were also asked whether or not they were suffering from a chronic disease as well as one or more common diseases prevailing among the elderly population in the country. Each disease was posed as a "Yes" or "No" question, and respondents reported their answers after being asked if they had any diseases/illnesses. These disease-questions included the following after first being asked about chronic disease: hypertension, arthritis, heart disease, lumbar vertebra problems, bronchitis, osteoporosis, cerebral disease, digestive tract problems, glaucoma/cataract problems, diabetes, prostatitis, respiratory disease, dermatosis, kidney failure, nervous system problems, stroke, liver issues, senile dementia, malignant tumors, and tuberculosis. 
Within the demographic characteristics, gender is a dichotomous variable measured by (1) Male and (2) Female. The next variable is age and it is recoded as an ordinal variable measured by three categories: (1) 60-69, (2) 70-79, and (3) $80+$. Fertility is referred to as the number of children born to the individual respondents. It is re-coded as an ordinal variable, measured by a four-point scale: (1) 0, (2) 1-2. (3) 3-4, and (4) 5+. Finally, marital status is a nominal variable and measured by (1) Married, (2) Divorced, (3) Widowed, and (4) Other.

The social characteristic variables include residence and education. Residence is an ordinal variable, measured by a three-point scale: (1) Rural, (2) Rural-Urban, and (3) Urban. Education is an ordinal variable and measured by the scale of (1) Elementary school, (2) Middle school, (3) High school, and (4) College and above.

Economic characteristics include four variables. The first is economic security and it is a nominal variable. Respondents were asked the question, "Do you think your economy is secure?" The measure is indicated by (1) No and (2) Yes. Next is the variable of economic perception. Respondents were asked the question "How do you personally perceive your economic situation?" It is measured by a five-point-scale indicator: (1) Very difficult, (2) Difficult, (3) Average, (4) Satisfactory, and (5) Very satisfactory. Pension is the third economic characteristic and is also an ordinal variable. Individuals were asked how valuable their pension is in monetary terms and their answers are recoded in three categories: (1) Less than 1000 yuan, (2) 1000-2000 yuan, and (3) 2100-4680 yuan. Likewise, personal savings is also an ordinal variable and measured by a four-point-scale: (1) 200-9000 yuan, (2) 10,000-20,000 yuan, (3) 25,000-50,000 yuan, and (4) 55,000-250,000 yuan.

Within the social resources there are three variables. First, the nominal variable of the state stipend was studied by asking respondents if they receive any state stipend. It is a nominal variable and measured by (1) No and (2) Yes. Kids' support is referred to as whether or not the elderly respondents receive any support from their children. It is a nominal variable and measured by (1) No and (2) Yes. Lastly, the variable of medical insurance is also measured. It is a nominal variable and asked as whether or not the elderly individual purchases medical insurance; it is recoded as (1) No and (2) Yes.

Finally, the category of psychological wellbeing includes four variables. Happiness is an ordinal variable. The data in this study is collected by asking the elderly if they feel happy about their life in general, measured by a threepoint-scale: (1) Unhappy, (2) Average, and (3) Happy. The variable loneliness is also ordinal and was collected through the question, "Are you feeling lonely?" It was measured by a three-point-scale: (1) Yes, (2) Hard to say, and (3) No. Family harmony is a nominal variable. Respondents answered the question, "Do you think that your family relationships are harmonious?" It is measured by replying: (1) No and (2) Yes. The final variable, memory loss, is also nominal. After answering, "Do you experience memory loss?" respondents either said (1) No or (2) Yes. 
Of the seventeen presumed independent variables, four are used as control variables: residence, marital status, age, and filial piety. Filial piety is an ordinal variable measured by a five-point-scale: (1) Very unfilial, (2) Unfilial, (3) Average, (4) Filial, and (5) Very filial. The primary purpose of the utilization of control variables is to expel a potential spurious relationship. The justification of the control variables lies in that residence might be a third variable behind the linkage between health status and gender; filial piety may be the antecedent of the effect on health by fertility; and the relationship may by carried away by marital status when analyzing the linkage between health and loneliness. Likewise, the relationship between health and memory loss may be due to the effect of age.

All of the mentioned variables were tested with the presumed dependent variable of health status.

\section{Statistical Methods}

The variables used in this study involve nominal, ordinal, and interval levels of measurement. Since the research objective is to examine the variability and the associations between the presumed dependent and the independent variables, it is appropriate to use the following corresponding methods: descriptive statistics and frequency distribution, correlations, Chisquare significance test, Cramer's V, and Tau-c (Fox 2002). The descriptive statistics are used to provide a general overview of the health status, including the common diseases of the Chinese elderly. The correlation matrix will present correlations between the health status of the Chinese elderly and their socioeconomic statuses, demographic characteristics, and psychological wellbeing. The Chi-square is applied to test the significance of the association of nominal variables. Cramer's V demonstrates the strength of the relationship among the nominal variables. Tau-c is best known for its ability to show magnitude between and among associations of ordinal variables (Fox 2002).

\section{Results}

This section summarizes the findings of the data analysis based upon the recorded responses and tests through descriptive statistics, percentages, crosstabulations, correlations, Chi-square significance tests, and the magnitude tests as shown by Cramer's V and Tau-c.

\section{Incidence of Diseases among the Chinese Elderly}

In terms of common diseases affecting the Chinese elderly, the results show variations among the elderly respondents. For a general picture, a total of 76.6 percent of those elderly surveyed reported to be suffering from a chronic disease. This represents a vast majority of the Chinese elderly. Less than half of the respondents, 41.4 percent, reported to suffer from hypertension. Those 
who reported to have arthritis equaled 29.4 percent, whereas 27.1 percent stated to have a heart disease. Lumbar vertebra problems, bronchitis, osteoporosis, cerebral diseases, digestive tract issues, and glaucoma/cataract troubles account for 10-20 percent of the population. Other diseases total less than 10 percent of the Chinese elderly. These results help to answer the question of which health issues are presently relevant to the population of the Chinese elderly. The diseases mentioned above represent a large part of the population and reveal significant information about the elderly.

Table 1. Variations of Common Diseases among the Chinese Elderly

\begin{tabular}{|l|c|c|c|}
\hline \multicolumn{1}{|c|}{ Diseases } & No & Yes & Total \\
\hline Chronic Disease & $461(23.4 \%)$ & $1512(76.6 \%)$ & $1973(100.0 \%)$ \\
\hline Hypertension & $886(58.6 \%)$ & $626(41.4 \%)$ & $1512(100.0 \%)$ \\
\hline Arthritis & $1068(70.6 \%)$ & $444(29.4 \%)$ & $1512(100.0 \%)$ \\
\hline Heart disease & $1102(72.9 \%)$ & $410(27.1 \%)$ & $1512(100.0 \%)$ \\
\hline Lumbar Vertebra & $1225(81.0 \%)$ & $287(19.0 \%$ & $1512(100.0 \%)$ \\
\hline Bronchitis & $1260(83.3 \%)$ & $252(16.7 \%)$ & $1512(100.0 \%)$ \\
\hline Osteoporosis & $1285(85.0 \%)$ & $192(12.7 \%)$ & $1512(100.0 \%)$ \\
\hline Cerebral Disease & $1301(86.0 \%)$ & $211(14.0 \%)$ & $1512(100.0 \%)$ \\
\hline Digestive Tract & $1320(87.3 \%)$ & $192(12.7 \%)$ & $1512(100.0 \%)$ \\
\hline Glaucoma/Cataract & $1328(87.8 \%)$ & $184(12.2 \%)$ & $1512(100.0 \%)$ \\
\hline Diabetes & $1392(92.1 \%)$ & $120(7.9 \%)$ & $1512(100.0 \%)$ \\
\hline Prostatitis & $1417(93.7 \%)$ & $95(6.3 \%)$ & $1512(100.0 \%)$ \\
\hline Respiratory Disease & $1420(93.9 \%)$ & $92(6.1 \%)$ & $1512(100.0 \%)$ \\
\hline Dermatosis & $1441(95.3 \%)$ & $71(4.7 \%)$ & $1512(100.0 \%)$ \\
\hline Kidney Failure & $1441(95.3 \%)$ & $71(4.7 \%)$ & $1512(100.0 \%)$ \\
\hline Nervous System & $1455(96.2 \%)$ & $57(3.8 \%)$ & $1512(100.0 \%)$ \\
\hline Stroke & $1456(96.3 \%)$ & $56(3.7 \%)$ & $1512(100.0 \%)$ \\
\hline Liver & $1477(97.7 \%)$ & $35(2.3 \%)$ & $1512(100.0 \%)$ \\
\hline Senile Dementia & $1486(98.3 \%)$ & $26(1.7 \%)$ & $1512(100.0 \%)$ \\
\hline Malignant Tumors & $1493(98.7 \%)$ & $19(1.3 \%)$ & $1512(100.0 \%)$ \\
\hline Tuberculosis & $1495(98.9 \%)$ & $17(1.1 \%)$ & $1512(100.0 \%)$ \\
\hline
\end{tabular}

\section{Health Status and Demographic Characteristics}

The variables tested within the demographic characteristic section include gender, age, fertility (the number of children the respondent reported to have), and marital status. When testing for gender, the numbers were quite equal for health status. The "So-so" category of health status has 48.6 percent male and 48.5 percent female. However, females show to have slightly higher numbers than males in the "Poor" and "Very poor" reports. Males show to have more numbers in the higher rated health status options of "Good" and "Very good". This relationship is found to be statistically significant. The result indicates that male elderly tend to report more positive health than female elderly, though the relationship is weak (Cramer's $V=.081$ ). After controlling for residence, the relationship between health status and gender still shows significance. The two categories of "Rural" and "Rural-Urban" show to be insignificant. This does 
suggest that gender still has an effect on health while residence does contribute to the variation of health status. It also implies that an individual's area of residence has an effect on health status, rather than simply gender alone (See Table 2 and Table 3 ).

Next, the result of the relationship between health status and age group, as expected, shows that older individuals tend to report more negative health status than younger individuals, whereas the young individuals tend to report a more positive health status. To illustrate, only 4.2 percent of respondents answered to have "Very poor" health within in the 60-69 year age-group compared to the much larger 14.3 percent of respondents to answer the same within the $80+$ year age-group. The "Very good" and "Good" age-groups also show much larger numbers amongst the younger respondents compared to the older respondents. The relationship is statistically significant though weakly and negatively associated (See Table 2).

The relationship between health status and fertility, namely the number of children an elder reported to have, shows to be statistically significant. However, the association is weak and negative. For example, the number of respondents who answered "Very good" in health status decreases as the number of children the respondents have increases. After controlling for the effect of filial piety, the results show that, though the overall relationship is still significant, the majority of the categories of the five-point-scale of filial piety show to be insignificant. This finding suggests that having more children does not necessarily add to the positive perception of the health status but the filial piety really increases positive perception.

Finally, the last variable of demographics, marital status, shows a significant relationship with health status though the association strength is relatively weak. Married and divorced respondents in the "Good" health category totaled 22.9 and 33.3 percent, respectively. At a much lower level is the 19.1 percent of those in the same category who are widowed.

\section{Health Status and Social Characteristics}

The social characteristics studied as the presumed independent variables include residence and education. These social variations among the Chinese elderly show connections and relationships with their reported health status. First, the variable of residence shows a very notable difference between those elderly living in rural areas versus those in urban. Reported rural residents have almost double the amount of individuals in the "Poor" and "Very poor" categories, compared to those in urban areas. The relationship is statistically significant with a moderate strength. The relationship between health status and education, however, resulted in having no statistical significance with a very weak Tau-c (.017). 
Table 2. Associations between Health Status and Demographic Characteristics

\begin{tabular}{|c|c|c|c|c|c|}
\hline Gender & \multicolumn{2}{|c|}{ Male } & \multicolumn{2}{|c|}{ Female } & Total \\
\hline Very Poor & \multicolumn{2}{|c|}{$63(6.2 \%)$} & \multicolumn{2}{|c|}{$65(6.8 \%)$} & $65(6.8 \%)$ \\
\hline Poor & \multicolumn{2}{|c|}{$172(16.9 \%)$} & \multicolumn{2}{|c|}{$210(21.8 \%)$} & $382(19.3 \%)$ \\
\hline So-So & \multicolumn{2}{|c|}{$494(48.6 \%)$} & \multicolumn{2}{|c|}{$467(48.5 \%)$} & $961(48.6 \%)$ \\
\hline Good & \multicolumn{2}{|c|}{$237(23.3 \%)$} & \multicolumn{2}{|c|}{$189(19.6 \%)$} & $426(21.5 \%)$ \\
\hline Very Good & \multicolumn{2}{|c|}{$50(4.9 \%)$} & \multicolumn{2}{|c|}{$31(3.2 \%)$} & $81(4.1 \%)$ \\
\hline Total & \multicolumn{2}{|c|}{$1016(100.0 \%)$} & \multicolumn{2}{|c|}{$962(100.0 \%)$} & $1978(100.0 \%)$ \\
\hline \multicolumn{5}{|c|}{$\chi^{2}=12.971 ; \quad$ df $=4$} & \\
\hline Age & $60-69$ & \multicolumn{2}{|c|}{ 70-79 } & 80+ & Total \\
\hline Very Poor & $37(4.2 \%)$ & \multicolumn{2}{|c|}{$51(6.2 \%)$} & $40(14.3 \%)$ & $128(6.5 \%)$ \\
\hline Poor & $126(14.4 \%)$ & \multicolumn{2}{|c|}{$182(22.0 \%)$} & $74(26.5 \%)$ & $382(19.3 \%)$ \\
\hline So-So & $440(50.5 \%)$ & \multicolumn{2}{|c|}{$391(47.3 \%)$} & $130(46.6 \%)$ & $961(48.6 \%)$ \\
\hline Good & $222(25.5 \%)$ & \multicolumn{2}{|c|}{$173(20.9 \%)$} & $31(11.1 \%)$ & $426(21.5 \%)$ \\
\hline Very Good & $47(5.4 \%)$ & \multicolumn{2}{|c|}{$30(3.6 \%)$} & $4(1.4 \%)$ & $81(4.1 \%)$ \\
\hline Total & $872(100.0 \%)$ & \multicolumn{2}{|c|}{$827(100.0 \%)$} & $\begin{array}{c}279 \\
(100.0 \%)\end{array}$ & $1978(100.0 \%)$ \\
\hline \multicolumn{6}{|c|}{$\mathrm{p} \leq .001$} \\
\hline Fertility & None & $1-2$ & $3-4$ & $5+$ & Total \\
\hline Very Poor & $4(11.1 \%)$ & $31(7.0 \%)$ & $56(5.9 \%)$ & $37(6.9 \%)$ & $128(6.5 \%)$ \\
\hline Poor & $4(11.1 \%)$ & $68(15.2 \%)$ & $184(19.2)$ & $126(23.4 \%)$ & $382(19.3 \%)$ \\
\hline So-So & $20(55.6 \%)$ & $228(51.1 \%)$ & $453(47.3 \%)$ & $260(48.2 \%)$ & $961(48.6 \%)$ \\
\hline Good & $5(13.9 \%)$ & $101(22.6 \%)$ & $225(23.5 \%)$ & $95(17.6 \%)$ & $426(21.5 \%)$ \\
\hline Very Good & $3(8.3 \%)$ & $18(4.0)$ & $39(4.1 \%)$ & $21(3.9 \%)$ & $81(4.1 \%)$ \\
\hline Total & $36(100.0 \%)$ & $\begin{array}{c}446 \\
(100.0 \%)\end{array}$ & $\begin{array}{c}957 \\
(100.0 \%) \\
\end{array}$ & $\begin{array}{c}539 \\
(100.0 \%) \\
\end{array}$ & $1978100.0 \%)$ \\
\hline $\begin{array}{l}\text { Marital } \\
\text { Status } \\
\end{array}$ & Married & Divorced & Widowed & Other & Total \\
\hline Very Poor & $73(5.8 \%)$ & $1(3.7 \%)$ & $48(7.5 \%)$ & $6(12.5 \%)$ & $128(6.5 \%)$ \\
\hline Poor & $221(17.6 \%)$ & $5(18.5 \%)$ & $149(23.1 \%)$ & $6(12.5 \%)$ & $381(19.3 \%)$ \\
\hline So-So & $619(49.2 \%)$ & $12(44.4 \%)$ & $301(46.7 \%)$ & $28(58.3 \%)$ & $960(48.6 \%)$ \\
\hline Good & $288(22.9 \%)$ & $9(33.3 \%)$ & $123(19.1 \%)$ & $6(12.5 \%)$ & $426(21.6 \%)$ \\
\hline Very Good & $56(4.5 \%)$ & $0(0.0 \%)$ & $23(3.6 \%)$ & $2(4.2 \%)$ & $81(4.1 \%)$ \\
\hline Total & $\begin{array}{c}1257 \\
(100.0 \%) \\
\end{array}$ & $27(100.0 \%)$ & $\begin{array}{c}644 \\
(100.0 \%) \\
\end{array}$ & $48(100.0 \%)$ & $\begin{array}{c}1976 \\
(100.0 \%) \\
\end{array}$ \\
\hline & $\chi^{2}=22.796$ & $\mathrm{df}=12$ & $\mathrm{p} \leq .05$ & Cramer's V= & .062 \\
\hline
\end{tabular}

Table 3. Associations between Health Status and Gender by Controlling for Residence

\begin{tabular}{|l|c|c|c|c|}
\hline Residence & $\boldsymbol{\chi}^{\mathbf{2}}$ & df & $\mathbf{p} \leq$ & Cramer's V \\
\hline Rural & 5.311 & 4 & n. s. $(.257 \%)$ & .074 \\
\hline Rural-Urban & 7.135 & 4 & n. s. $(.129 \%)$ & .244 \\
\hline Urban & 10.929 & 4 & .05 & .112 \\
\hline Total & 13.422 & 4 & .01 & .082 \\
\hline
\end{tabular}


Table 4. Associations between Health Status and Fertility by Controlling for Filial Piety

\begin{tabular}{|l|c|c|}
\hline Filial Piety & Tau-c & p $\leq$ \\
\hline Very Unfilial & -.042 & n. s. $(.196)$ \\
\hline Unfilial & -.041 & n. s. $(.105)$ \\
\hline Average & -.097 & .05 \\
\hline Filial & .073 & n. s. $(.486)$ \\
\hline Very Filial & .293 & n. s. $(.198)$ \\
\hline Total & -.051 & n. s. $(.198)$ \\
\hline
\end{tabular}

Table 5. Associations between Health Status and Social Characteristics

\begin{tabular}{|c|c|c|c|c|c|c|c|}
\hline Residence & \multicolumn{2}{|l|}{ Rural } & \multicolumn{2}{|c|}{ Rural-Urban } & \multicolumn{2}{|c|}{ Urban } & Total \\
\hline Very Poor & \multicolumn{2}{|c|}{$74(7.5 \%)$} & \multicolumn{2}{|c|}{$12(10.0 \%)$} & \multicolumn{2}{|c|}{$42(4.8 \%)$} & $128(6.5 \%)$ \\
\hline Poor & \multicolumn{2}{|c|}{$236(24.1 \%)$} & \multicolumn{2}{|c|}{$17(14.2 \%)$} & \multicolumn{2}{|c|}{$128(14.6 \%)$} & $381(19.3 \%)$ \\
\hline So-So & \multicolumn{2}{|c|}{$427(43.5 \%)$} & \multicolumn{2}{|c|}{$53(44.2 \%)$} & \multicolumn{2}{|c|}{$481(55.0 \%)$} & $961(48.6 \%)$ \\
\hline Good & \multicolumn{2}{|c|}{$209(21.3 \%)$} & \multicolumn{2}{|c|}{$32(26.7 \%)$} & \multicolumn{2}{|c|}{$184(21.0 \%)$} & $425(21.5 \%)$ \\
\hline Very Good & \multicolumn{2}{|c|}{$35(3.6 \%)$} & \multicolumn{2}{|c|}{$6(5.0 \%)$} & \multicolumn{2}{|c|}{$40(4.6 \%)$} & $81(4.1 \%)$ \\
\hline Total & $981(100.0$ & & $120(100$ & $.0 \%)$ & 875 & $(100.0 \%)$ & $1976(100.0 \%)$ \\
\hline & \multicolumn{2}{|c|}{$\chi^{2}=46.842$} & $\mathrm{df}=8$ & $\mathrm{p} \leq$ & \multicolumn{2}{|c|}{.001 ;Cramer's } & $\mathrm{V}=.109$ \\
\hline Education & $\begin{array}{c}\text { Elementary } \\
\text { School } \\
\end{array}$ & \multicolumn{2}{|c|}{$\begin{array}{l}\text { Middle } \\
\text { School }\end{array}$} & \multicolumn{2}{|c|}{ High School } & College & Total \\
\hline Very Poor & $41(5.4 \%)$ & \multicolumn{2}{|c|}{$6(2.5) \%$} & \multicolumn{2}{|c|}{$6(3.2 \%)$} & $4(4.4 \%)$ & $57(4.5 \%)$ \\
\hline Poor & $140(18.3 \%)$ & \multicolumn{2}{|c|}{$30(12.6 \%)$} & \multicolumn{2}{|c|}{$20(10.8 \%)$} & $14(15.4 \%)$ & $204(15.9 \%)$ \\
\hline So-So & $352(46.1 \%)$ & \multicolumn{2}{|c|}{$143(60.1 \%)$} & \multicolumn{2}{|c|}{$105(56.5 \%)$} & $51(56.0 \%)$ & $651(50.9 \%)$ \\
\hline Good & $194(25.4 \%)$ & \multicolumn{2}{|c|}{$52(21.8) \%$} & \multicolumn{2}{|c|}{$45(24.2 \%)$} & $20(22.0 \%)$ & $311(24.3 \%)$ \\
\hline Very Good & $37(4.8 \%)$ & \multicolumn{2}{|c|}{$7(2.9 \%)$} & \multicolumn{2}{|c|}{$7(2.9 \%)$} & $2(2.2 \%)$ & $56(4.4 \%)$ \\
\hline Total & $764(100.0 \%)$ & \multicolumn{2}{|c|}{$\begin{array}{c}238 \\
(100.0 \%)\end{array}$} & \multicolumn{2}{|c|}{$\begin{array}{c}186 \\
(100.0 \%)\end{array}$} & $91(100.0 \%)$ & $\begin{array}{c}1279 \\
(100.0 \%)\end{array}$ \\
\hline
\end{tabular}

\section{Health Status and Economic Characteristics}

Findings show that economic characteristics represented by economic security, economic perception, pension, and personal savings have an effect on health status.

Economic security shows much greater numbers of decent health status for those who reported feeling economically secure. Those who do not feel economically secure had higher scores in the "Poor" and "Very poor" categories with differences as large and 13.1 percent and 8.2 percent, respectively. These same results are also reflected in the responses of those with "Good" and "Very good" health status. This relationship is quite statistically significant and also moderately strong (See Table 6).

The variable of economic perception and its relationship with health status shows a relatively high level of statistical significance, and has a noteworthy, moderate and positive relationship. The respondent totals directly show that as one's economic perception increases, their health status does as well. This trend is seen in every category of health status as the perception increases. The results of the other two variables representing economic characteristics, the possession of a pension measured in terms of money by the Chinese elderly and personal savings, have similar findings. Both pension and personal savings 
also show statistically significant relationships with health status, with apparent variations of the magnitudes (See Table 6).

Table 6. Associations between Health Status and Economic Characteristics

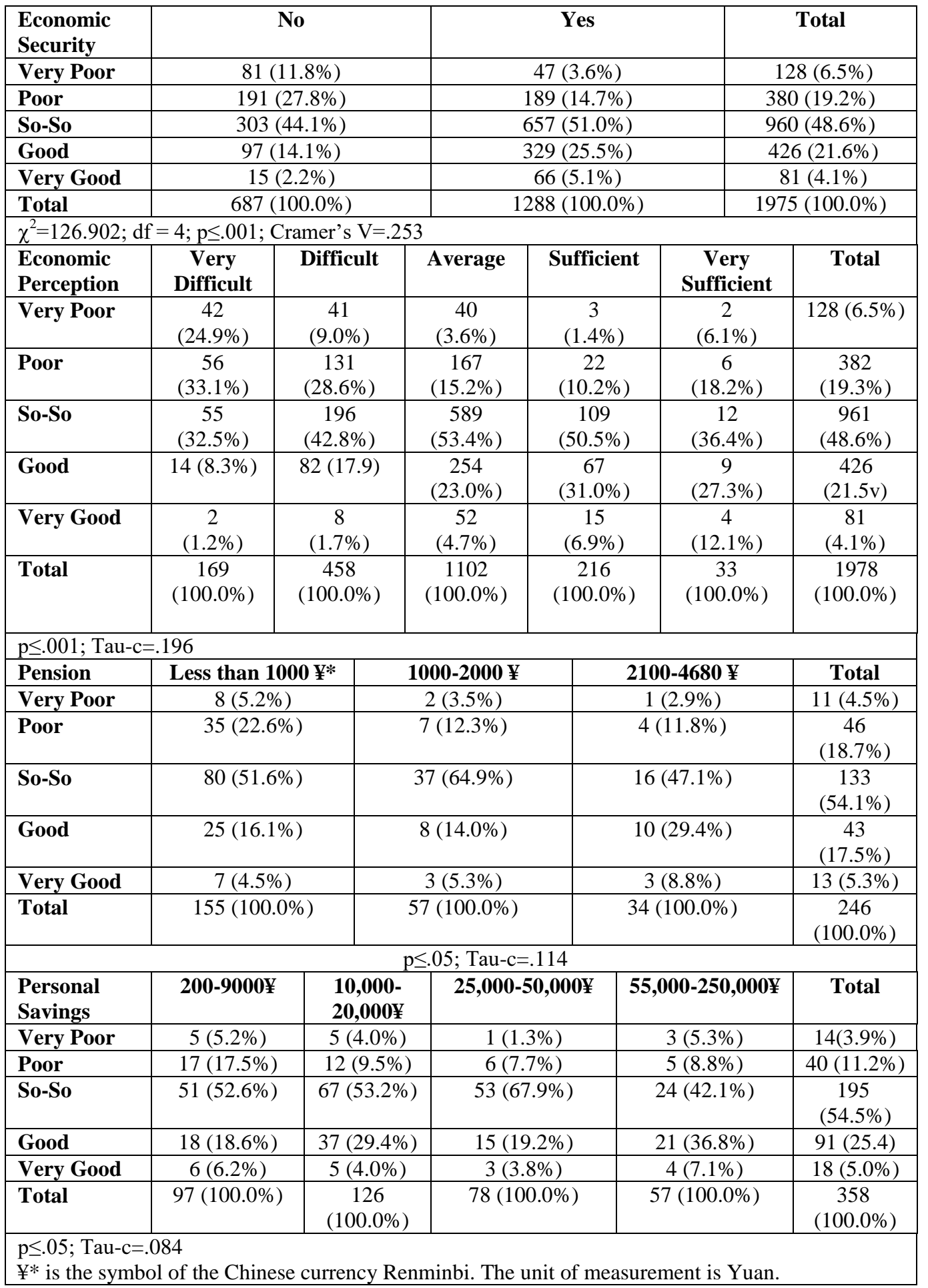




\section{Health Status and Social Resources}

Social resource variables include the presence of a state stipend, support from the respondents' children, and medical insurance. In this study, the relationship between health status and a state stipend is statistically significant, with a moderately strong relationship. Interestingly, those without a state stipend reported better health status. Those without a state stipend in the "Very poor" health category total only 5.3 percent while those with a state stipend who reported "Very poor" health total 19.3 percent. This trend continues in the data with the majority of healthier respondents without a state stipend. This result might imply that the poor receive state stipend and are dependent upon it. It is very likely the state stipend is far from being sufficient enough to shift the overall negative situation of the poor elderly.

Another indicator of social resources for the Chinese elderly comes from the support by children. The results show that children's support is in a statistically significant relationship with their elderly population's health status. It is a weak, but positive association between the variables. Results of this test are quite similar for each of the categories, suggesting that support of elderly from children is positive and significant. Though the differences between these percentages are small, it can still be shown that support from children does play a role in predicting health status. The last indicator of social resources is medical insurance. However, this relationship is shown to have no statistical significance with health status, and also a weak association.

Table 7. Associations between Health Status and Social Resource

\begin{tabular}{|c|c|c|c|}
\hline State Stipend & No & Yes & Total \\
\hline Very Poor & $96(5.3 \%)$ & $32(19.3 \%)$ & $128(6.5 \%)$ \\
\hline Poor & $348(19.2 \%)$ & $34(20.5 \%)$ & $382(19.3 \%)$ \\
\hline So-So & $889(49.1 \%)$ & $71(42.8 \%)$ & $960(48.6 \%)$ \\
\hline Good & $401(22.2 \%)$ & $25(15.1 \%)$ & $426(21.6 \%)$ \\
\hline Very Good & $76(4.2 \%)$ & $4(2.4 \%)$ & $80(4.0 \%)$ \\
\hline Total & $1810(100.0 \%)$ & $166(100.0 \%)$ & $1976(100.0 \%)$ \\
\hline \multicolumn{4}{|c|}{$\chi^{2}=51.986 ; \mathrm{df}=4 ; \mathrm{p} \leq .001 ;$ Cramer's $\mathrm{V}=.162$} \\
\hline Kids' Support & No & Yes & Total \\
\hline Very Poor & $78(7.9 \%)$ & $50(5.1 \%)$ & $128(6.5 \%)$ \\
\hline Poor & $180(18.1 \%)$ & $202(20.5 \%)$ & $382(19.3 \%)$ \\
\hline So-So & $494(49.7 \%)$ & $466(47.4 \%)$ & $960(48.6 \%)$ \\
\hline Good & $197(19.8 \%)$ & $229(23.3 \%)$ & $426(21.6 \%)$ \\
\hline Very Good & $44(4.4 \%)$ & $36(3.7 \%)$ & $80(4.0 \%)$ \\
\hline Total & $80(4.0 \%)$ & $983(100.0 \%)$ & $1976(100.0 \%)$ \\
\hline \multicolumn{4}{|c|}{$\chi^{2}=11.362 ; \mathrm{df}=4 ; \mathrm{p} \leq .05 ;$ Cramer's $\mathrm{V}=.076$} \\
\hline Medical Insurance & No & Yes & Total \\
\hline Very Poor & $122(6.5 \%)$ & $6(5.8 \%)$ & $128(6.5 \%)$ \\
\hline Poor & $363(19.4 \%)$ & $19(18.4 \%)$ & $382(19.3 \%)$ \\
\hline So-So & $912(48.6 \%)$ & $49(47.6 \%)$ & $961(48.6 \%)$ \\
\hline Good & $405(21.6 \%)$ & $21(20.4 \%)$ & $426(21.5 \%)$ \\
\hline Very Good & $73(3.9 \%)$ & $8(7.8 \%)$ & $81(4.1 \%)$ \\
\hline Total & $1875(100.0 \%)$ & $103(100.0 \%)$ & $1978(100.0 \%)$ \\
\hline
\end{tabular}




\section{Health Status and Psychological Wellbeing}

This section reports the findings relating the linkage between health status and psychological wellbeing. In this study, the indicators of happiness, feelings of loneliness, family harmony, and memory loss measure psychological wellbeing as the presumed independents.

The relationship between health status and happiness is statistically significant, positively related, and moderate in strength. The happier a respondent reported to be, the better their health status. In virtually every different health status level, happiness proves to have a beneficial effect. This relationship is consistent and very noticeable within the Chinese elderly population (See Table 8).

Health status and loneliness show to be in a statistically significant relationship with a moderate-to-strong and positive association. Results show that when feelings of loneliness decrease, perceived health status increases. It is tentatively concluded that loneliness has an effect on the health status of the elderly population in China, with notable difference in each section of percent results (See Table 8). To test if the relationship between health status and loneliness is spurious, marital status is introduced as a control variable with the argument that marital status may have an effect on both health status and the feeling of loneliness. Results indicate that the relationship between health and loneliness is still statistically significant with a moderate strength. In the four categories of marital status, two of them, "Divorced" and "Other" show to be statistically insignificant (See Table 9). This test suggests that though marital status is not the antecedent variable, it does play a role in the respondent's health status perception and their feelings of loneliness. Combining all three variables together, we may conclude that feelings of loneliness do have a connection to health status with the addition of marital status to this model, confirming the assumption that health perception is linked to people's feelings of loneliness.

Family harmony is also important in relating to the health status of Chinese elderly. The results show that those individuals who report to have family harmony experience better health than those who do not. Out of respondents with "Very poor" health, 21.5 percent report to have no family harmony while only 5.9 percent report to have family harmony. This trend continues in the rest of the categories with comparable difference between the two options of family harmony. The relationship is statistically significant and has a moderate strength. The result shows that those Chinese elderly with family harmony are likely to have a better health status than those without (See Table 8).

Lastly, the psychological variable of memory loss also shows a statistically significant relationship with health status and a notably moderate-to-strong relationship. This result demonstrates that those who do not experience memory loss report to have better health than those who do experience memory loss. The finding suggests that there is a relatively strong association between health status and memory loss. Given the argument that memory loss might be 
contributed to by aging, the control variable of age was introduced in an effort to verify the relationship between health and memory. The result shows that the relationship was still statistically significant with a moderately strong connection between health and memory loss. This suggests that the control variable of age is not an antecedent variable while the respondents' memory loss does show effect on elderly health status.

Table 8. Associations between Health Status and Psychological Being

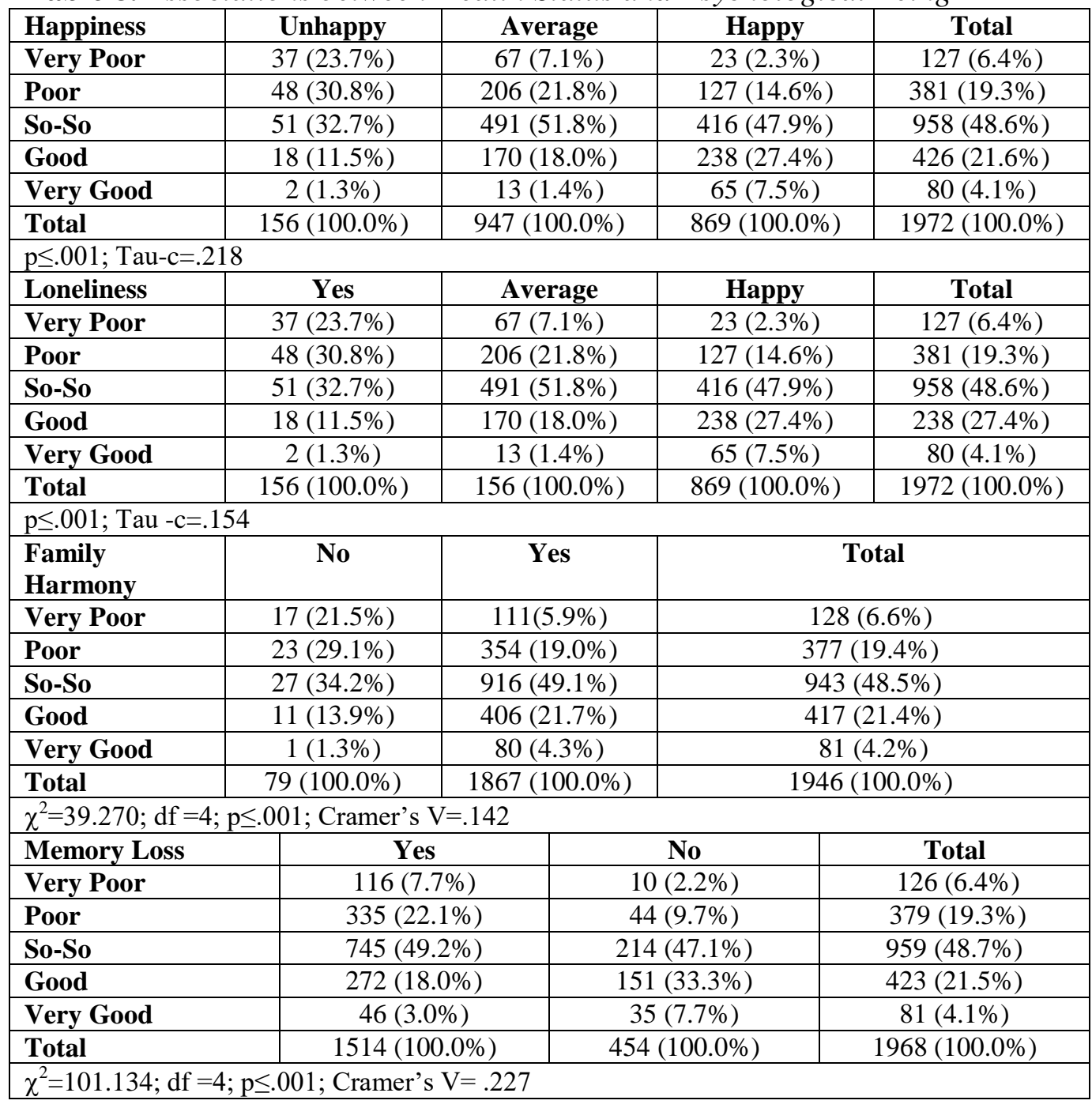

Table 9. Associations between Health Status and Loneliness by Controlling for Marital Status

\begin{tabular}{|l|c|c|}
\hline Marital Status & Tau-c & $\mathbf{p} \leq$ \\
\hline Married & .150 & .001 \\
\hline Divorced & .008 & n. s. $(.980)$ \\
\hline Widowed & .132 & .001 \\
\hline Other & .158 & n. s. $(.191)$ \\
\hline Total & .154 & .001 \\
\hline
\end{tabular}


Table 10. Associations between Health Status and Memory Loss by Controlling for Age

\begin{tabular}{|l|c|c|c|c|}
\hline Age Group & $\boldsymbol{\chi}^{\mathbf{2}}$ & df & p $\leq$ & Cramer's V \\
\hline $\mathbf{6 0 - 6 9}$ & 55.087 & 4 & .001 & .252 \\
\hline $\mathbf{7 0 - 7 9}$ & 24.813 & 4 & .001 & .174 \\
\hline $\mathbf{8 0 +}$ & 9.620 & 4 & .05 & .186 \\
\hline Total & 101.134 & 4 & .001 & .227 \\
\hline
\end{tabular}

\section{Discussion and Conclusion}

To conclude, these findings show consistent support of the theories and hypotheses under study. Demographic characteristics, social characteristics, economic status, social resources, and psychological wellbeing are associated with the health status of the Chinese elderly. A majority of the 17 presumed independent variables did show to have an effect on the presumed dependent variable of health status, being either correlated or associated with control variables.

This study confirms that the top ten diseases do represent a good number of the Chinese elderly, as well as the representative respondents that added information to the research. These findings also confirm the first hypothesis the perceived health status among the Chinese elderly varies within this population. Results came from different ages of elderly, in many different areas, with individuals in each category of the range of health status. The findings were in agreement with the literature in terms of the afflicting diseases, while only different in amount. In addition, many of the variables support the Social Resource Theory. Many of the results show that positive responses equal positive health status. More importantly, the findings largely support the hypotheses that health status of the Chinese elderly is correlated and associated with their demographic characteristics, socioeconomic statuses, social resources, and psychological wellbeing. The findings also confirm that active social ties, roles, resources, and psychological wellbeing lead to better life quality in health.

Demographic characteristics tested to show an effect on the health status of the elderly population in China. This is in alignment with theory and literature. Gender was a significant variable, with males showing to have slightly better health status than females. This finding might be expected in China due to historical male preference in society, however this might be an area of interest for future studies as culture in China continues to change and evolve. Decreased amounts of difference between the genders were a notable finding in this study. The introduction of the control variable of residence suggests that the health status of Chinese elderly then appears to be a result of both residence and gender, rather than gender alone. These numbers help to explain the need for better health care options in order to help raise health status among its rural elderly population. Age was also a significant predictor of health status. The relationship is negative, an indication that as age increases; health status will decrease in the population of the Chinese elderly. 
This relationship is generally expected because the findings are consistent with the Aging Theory and the literature.

Additionally, fertility has a significant effect on health status. As a slight trend, those Chinese elderly with more children tended to have worse health than those with fewer children. However, when studying this culture it is important to incorporate filial piety. Using filial piety as a control variable, it was found that children, who are filial and care for their parents, have more of an effect on elderly health status, rather than solely the number of children the respondents had. This result means changes have been made in modern Chinese society. Filial piety is still relevant, especially when concerned with elderly members of society who are the most close to traditional culture. Care of the aging Chinese is largely put upon their children; those who report filial children are most likely looking to receive care from them, and in turn experience a better health status (Ji and Wells 2014). Subsequently, having more children who are not filial might poorly affect health. This finding also confirms the study by $\mathrm{Ji}$ and Wells that it is filial piety, not the number of children that is the biggest concern of the elderly. Regarding the effect of marital status, the findings are consistent with theory. Marital status, compared with being divorced, widowed, and other, is by far the most important predictor on health status. In a society that depends greatly on family, these findings support the notion that in China, traditional ways of marital life attribute the elderly to positive health status.

The relationship between health status and education resulted in no significance, which opposes the idea of education being very valuable for all aspects of life, as believed in western society. The primary reason might lie in the fact that this group of sampled elderly, due to the cohort effect, was born around the 1930s or 40s and therefore received little or no education. The education was primarily concentrated in elementary levels; therefore their health status has little to do with their educational attainment.

Also in support of the proposed theories as well as the previous literature, are the relationships between economic characteristics and health status. The Political Economy Theory is seen in action within these variables. First, economic security is shown to be related to health status, as those who reported to feel economically secure also reported to have better health status. This is also seen in economic perception where those with better health status also reported to have a better perception of their economic situation. Further explanation is also noted in the proposed independent variables of pension and personal savings. In both tests, respondents who reported to have large pensions and personal savings also reported to have a better health status. These findings are also in line with theory and literature.

Social resources show a significant relationship to the health status of the elderly Chinese population. The possession of a state stipend showed to be associated with poor health. The reason for this result may lie in the fact that state stipend is received only by a small fraction of the elderly. Only those elderly who are extremely poor and in rough circumstances can be considered for the stipend. To add to the Political Economy Theory, those with more 
assets reap benefits. Support from children resulted in slightly better health status for the elderly. Due to the tradition of children in China being responsible for their parents as they age and need care, the variable of state stipend and medical insurance is new to the data of Chinese population. In western society, state stipends for elderly after they retire have become a staple of life expectancy.

The Social Competence and Breakdown Theory is especially reflected within psychological wellbeing. As social and other life aspects of an elderly individual start to change or breakdown, health status suffers. For example, this study shows that those who report to be less happy also report to have poor health. Loneliness also has a role in health status, as those who reported feelings of loneliness also show to have poor health status. As social connections, resources, or positive feelings decrease, life quality declines as well - as described by the Social Competence and Breakdown Theory. As expected, support in the acknowledged independent variables of family harmony and memory loss does have an effect on health. Respondents who report to have no family harmony, as well as those who reported to experience memory loss, show poor health. Therefore, maintaining social competence throughout life is important to having a good health status.

In sum, this study has shed light on the situation of the health status of the Chinese elderly. These findings can be used as references to the larger elderly population in the Chinese society and lead to more studies to expand knowledge in this area. The significant relationships found in this study illustrate positives and negatives in Chinese society and point to possible areas of improvement for policy makers as well as those working in governmental spheres.

\section{References}

Bengtson VL, Rice CJ, Johnson ML (1999) Are theories of aging important? Models and explanations in gerontology at the turn of the century. In VL Bengtson, KW Schaie (Eds), Handbook of Theories of Aging, 3-20. New York: Springer Publishing.

Chen F, Liu G (2009) Population aging in China. In P Uhlenberg (Ed) International handbook of population aging, 157-172. Amsterdam: Springer Publishing.

Cheng ST, Chan ACM (2006) Filial Piety and Psychological Well-Being in Well Older Chinese. Journal of Gerontology: Psychological Sciences 61(5): 262-269.

Chung W (2006) The Role of Medical Care in Explaining the Link between Health and Economic Resources. ASEAN Economic Bulletin 23(1): 45-56. Institute of Southeast Asian Studies (ISEAS).

Fang H, Chen J, Rizzo JA (2009) Explaining Urban-Rural Health Disparities in China. Medical Care 47(12): 1209-1216. Retrieved from bit.ly/1LCbK19.

Fox W (2002) Social Statistics: A Text Using MicroCase. 4th ed. Belmont, CA: Wadsworth, Print.

Henslin JM (2008) Sociology, a Down-To-Earth Approach, $9^{\text {th }}$ Edition. Pearson Learning Publishing House. 
Hesketh T, Li L, Xing ZW (2005) The Effect of China's One-Child Family Policy after 25 Years. Health Policy Report, the New England Journal of Medicine 353:1171-1176.

Hu ZF, Khan MS (1997) Why is China growing so fast?. Staff Papers-International Monetary Fund: 103-131.

Ji J, Wells AK (2014) Socioeconomic-Demographic Characteristics and Supporting Resources of the Chinese Elderly. Canadian Social Science 10(5): 153-167.

Leung K-K, Wu E-C, Lue B-H, Tang L-Y (2004) The Use of Focus Groups in Evaluating Quality of Life Components Among Elderly Chinese People. Quality of Life Research 13(1): 179-190.

Liu G, Zhang Z (2004) Sociodemographic Differentials of the Self-Rated Health of the Oldest-Old Chinese. Population Research and Policy Review 23(2): 117-133.

People's Daily (2014) Top Ten Killer Disease of Chinese. Retrieved from bit.ly/1Qwo6iN. [Accessed June 20, 2015].

Putnam M (2002) Linking aging theory and disability models: Increasing the potential to explore aging with physical impairment. The Gerontologist 42(6): 799-806.

Passuth P, Bengston V (1995) Sociological Theories of Aging: Current Perspectives and Future Directions. In JS Quadagno, D Street, Aging for the Twenty-First Century: Readings in Social Gerontology, 19-20. New York: St. Martin's.

Seibert SE, Kraimer ML, Liden RC (2001) A Social Capital Theory of Career Success. The Academy of Management Journal 44(2): 219-237.

United Nations (2010) Department of Economic and Social Affairs, Population Division World Population Prospects. Retrieved from http://bit.ly/20POS5i. [Accessed June 20, 2015].

United Nations (2011-2012) China, Total Fertility Rate - Average Number of Children per Woman in China, Europe, USA and India: 1950-2100. Retrieved from bit.ly/20POS5i. [Accessed June 20, 2015].

Zhang T, Chen Y (2006) Meeting the Needs of Elderly People in China. BMJ: British Medical Journal 333(7564): 363-364. Retrieved from 1.usa.gov/1oxdd3H. 